\title{
Locomotor Activity and Anxiety Changes With Acute and Chronic Exposure to Cigarette Smoke in Mice
}

\author{
Deniz Demirci ${ }^{1}$, Emre Dilbaz ${ }^{2}$, Firuzan $\mathrm{Akar}^{3}$ \\ ${ }^{1}$ Dept. of Sports Physiology, Faculty of Sports Sciences, Kocaeli University, Kocaeli, Turkey \\ ${ }^{2}$ Faculty of Sports Sciences, Kocaeli University, Kocaeli, Turkey \\ ${ }^{3}$ Dept. of Pharmacology, Shool of Medicine, Kocaeli University, Kocaeli, Turkey \\ Correspondence: Deniz Demirci, Dept. of Sports Physiology, Faculty of Sports Sciences, Kocaeli University, Kocaeli, \\ Turkey
}

Received: December 11, 2017

Accepted: February 4, $2018 \quad$ Online Published: April 1, 2018

doi:10.11114/jets.v6i3a.3164

URL: https://doi.org/10.11114/jets.v6i3a.3164

\begin{abstract}
The aim of this study was to investigate the locomotor activity and anxiety changes in acute and chronic exposure to cigarette smoke in mice. In the chronic exposure group, mice were exposed to the smoke of 10 cigarettes for 5 days a week, over 5 consecutiveweeks. In the acute group, the mice were exposed to the smoke of 10 cigarettes in one day. Locomotor activity tests and plus-maze tests were performed to determine the locomotor activity and anxiety levels of these mice. In the chronic exposure group, comparing with the both acute exposure and the control groups all parameters tested including distance travelled ( $p<0.001)$, velocity of locomotor activity test $(p<0.001)$, percentage of entrance through the open arm $(p<0.001)$, and the duration of staying in the open arm of the plus-maze test $(p<0.001)$ were significantly decreased .It has been concluded that the chronic cigarette smoke exposure resulted in decreased locomotor activity and increased anxiety levels in mice.
\end{abstract}

Keywords: acute cigarette smoke exposure, anxiety, chronic cigarette smoke exposure, locomotor activity, mice, plus-maze test.

\section{Introduction}

Active or passive cigarette smoke exposure causes chronotropic incompetency in the heart, a decreased heart rate response to exercise, increased tendency to atherosclerosis, decreased alveolar ventilation, decreased diffusion capacity, increased airway resistance, decreased blood oxygenation capacity, and tendency of coagulation compared to that seen in non-smokers (Taylor et al., 1992; Otsuka et al., 2001). It has been reported that cigarette smoke exposure leads to a decrease in exercise capacity in athletes (Kaleli, 2010; Soyuer, 2011). The negative effects of cigarette smoke exposure in different organs and tissues has been reported using results from in-vitro studies. However, the number of in-vivo studies related to cigarette smoke exposure reported in the literature is comparitively low (Aronson et al., 2008; Valenti et al., 2014; Moylan et al., 2013).

In this study, we aimed to evaluate locomotor activity and anxiety changes in chronic and acute cigarette smoke exposure in mice.

\section{Method}

\subsection{Animals}

Male, inbred BALB/c ByJ 6 week old mice that weighed 25 to $35 \mathrm{~g}$ (Bogazici University, Istanbul, Turkey), were used in this study. The animals were kept under standard laboratory conditions (12-h light: 12-h dark cycle, lights on at 07: $00 \mathrm{~h}, \mathrm{~T}=21 \pm 1^{\circ} \mathrm{C}$ ). The animals had access to food and water ad libitum.

$70 \mathrm{BALB} / \mathrm{c}$ mice were divided into 3 groups: chronic exposure ( 40 mice), acute exposure (15 mice), and control group (15 mice). In the chronic exposure group, the mice were exposed to the smoke of 10 cigarettes 5 days a week for 5 consecutive weeks. In the acute group, the mice were exposed to the smoke of 10 cigarettes in one day. Cigarettes containing $10 \mathrm{mg}$ tar and $0.8 \mathrm{mg}$ nicotine were used. Locomotor activity level was measured using Ethovision equipment. Additionally, a plus maze test was performed to measure the anxiety levels of the mice. 


\subsection{Smoke Exposure System Equipment}

The experiments were performed in a system specifically designed to test cigarette smoke exposure. The system was composed of a generator, mixture and dilution chamber, smoke exposure chamber and their side parts.

\subsection{Locomotor Activity Measurement}

Locomotor activity was measured using an open field test in a square arena $(40 \times 40 \times 40 \mathrm{~cm}$ box). The animals were placed in the center of the apparatus, and behavior was recorded for 5 minutes using a Etovision-XT video tracking system. The locomotor activity was evaluated by measuring the total distance traveled and speed the animals moved in the apparatus during the 5 minutes.

\subsection{Anxiety Measurement With Plus Maze (PM)}

Anxiety experiments were conducted in a PM room which is lit with a 80 lux table lamp. PM is a semi-soundproof wooden room and is elevated $40 \mathrm{~cm}$ from the floor. It consists of 2 open arms and 2 closed arms. These arms are $29 \mathrm{~cm}$ long $\times 5 \mathrm{~cm}$ wide which form a cross having a $5-\mathrm{cm}$ center space. Open arms were closed using a short Plexiglass edge so that the mice would not fall. The open arms and central part were colored white, and the closed arms were colored black.

Each mouse faced one of the open arms so that it was able to explore the maze by starting from the center for a 5 minute test period. The number of entries the nouse made into either the open or the closed arms and the time spent at the open arms were recorded.

The mouce's activity at the open arms were captured as follows:

- The percentage ratio of $t$ time spent at the open arms to the total time in the plus maze.

- The percentage ratio of open arm entries to the total number of open and closed arm entries.

These values were indicators to determine anxiety in mice (Demirci et al. 2014, Yildiz et al. 2000). The changes for both measured parameters were compared to that of the control group.

If either or both of the above measurements changed significantly, it was considered that anxiety in the mouse occurred. In our study, the open arm entry number and the time spent at the open arms changed.

The animals which fell from the maze were not included in the study results.

\subsection{Anxiety Measurement}

The PM test has been used to determine the effects of cigarette on anxiety. Two separate indicators were used as an index during the test.

The first indicator shows the percentage of the number of times a mouse enetered the open branch compared to the total number of entries (entries to both closed and open branches) during a 5 minute PM test.

$$
\text { Anxiety Level }=\frac{\text { Open Branch Entry Number }}{\text { Total Entry Number }} \times 100
$$

The second indicator gives the percentage of the duration of stay in the open branch compared to the total duration of the experiment (ie 5 minutes).

$$
\text { Anxiety Level }=\frac{\text { Duration of Stay in Open Branches }}{\text { Total Duration of the Experiment }} \times 100
$$

The parallelism of the two indicators and either one or both of the indicators being statistically significant were considered a measure of anxiety. It is reported in the literature that the statistical significance of this test, which is obtained from these two demonstrations, can adequately reflect the level of anxiety (Yildiz, 2000).

\subsection{Statistics}

The locomotor activities and the PM test results were compared using a one-way ANOVA, followed by Tukey's post hoc test if there was a significant difference. When the $\mathrm{p}$ value was less than 0.05 , the difference was considered to be statistically significant for this study.

The procedures performed in the study were conducted according to the directive for the Ethical Treatment of Animals (86/609/EEC) of the European Community Council and approval was obtained from the animal research ethics committee of the University (number 5/7 2014). 


\section{Findings}

Table 1. Effects of Acute and Chronic Cigarette Exposure on the Percentage of Duration of Stay in Open Branch during the Maze Test (+)

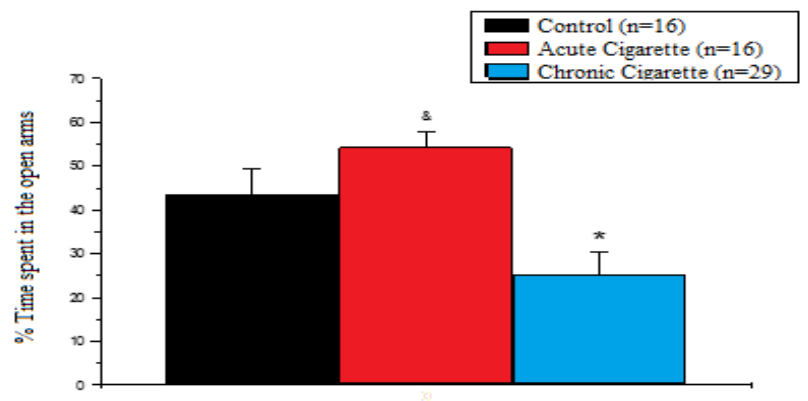

(Figures inside the brackets show the number $\mathrm{n}$ ) $* \mathrm{P}<0.05 \& \mathrm{p}<0.001$

Table 2. Effects of Acute and Chronic Cigarette Exposure on Entries to the Open Branch Percentage in the Maze Test $(+)$

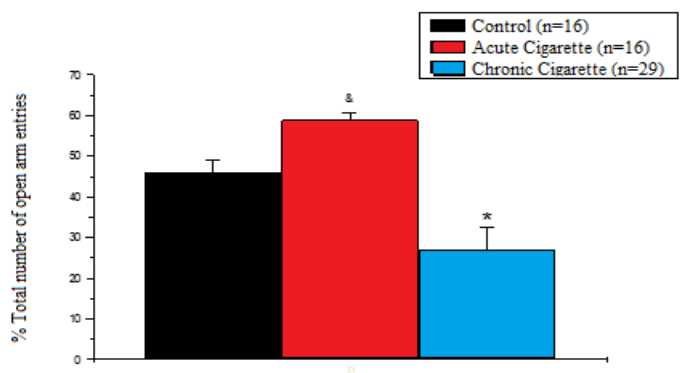

(Figures inside the brackets show the number $\mathrm{n}) * \mathrm{P}<0.01 \& \mathrm{p}<0.001$

Looking over the percent ratio of the number of entries to the open branch to total number of entries (entries to both open \& closed branches), it was seen that acutely affected had a higher percentage of entry than the control group. No data with statistical significance was found. On the other hand, the number of entries to open branch by the chronically affected decreased meaningfully in comparison to the control group $(* \mathrm{P}<0.01$ Difference Between Control Group and the Chronically Affected). Furthermore, it was also discovered that acutely and chronically affected had different amounts of entries to open branches (\&p<0.001 Difference Between Acutely and Chronically Affected). F(2, 49)=14.03

Table 3. Effects of Acute and Chronic Cigarette Exposure on Total Distance Traveled During Locomotor Activity Test

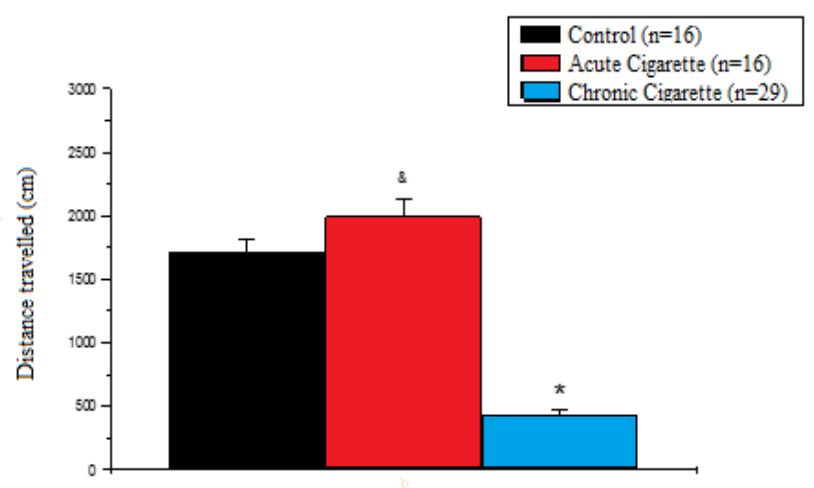

Locomotor Activity Test $* \mathrm{P}<0.001 \& \mathrm{p}<0.001$ 
Total distance traveled and speed parameters of the mice have been evaluated, while being monitered by Etho-Vision Video Tracking Software, for five minutes during which the mice were put to the center of the locomotor activity device.

After evaluating the total distance covered during the Locomotor Activity Test, it was found that the acutely affected covered a longer distance then the control group. This did not a statistical meaning. Yet unlike the former, chronic exposure to cigarettes had severely decreased the distance covered in comparison to the control group. (* $\mathrm{p}<0.001$ Difference Between Control Group and the Chronically Affected). In addition to that, there was a meaningful difference between acutely and chronically affected. (\&p<0.001 Difference Between Acutely and Chronically Affected) F(2, 58) $=106.12$

Table 4. Effects of Acute and Chronic Cigarette Exposure on Speed During Locomotor Activity Test

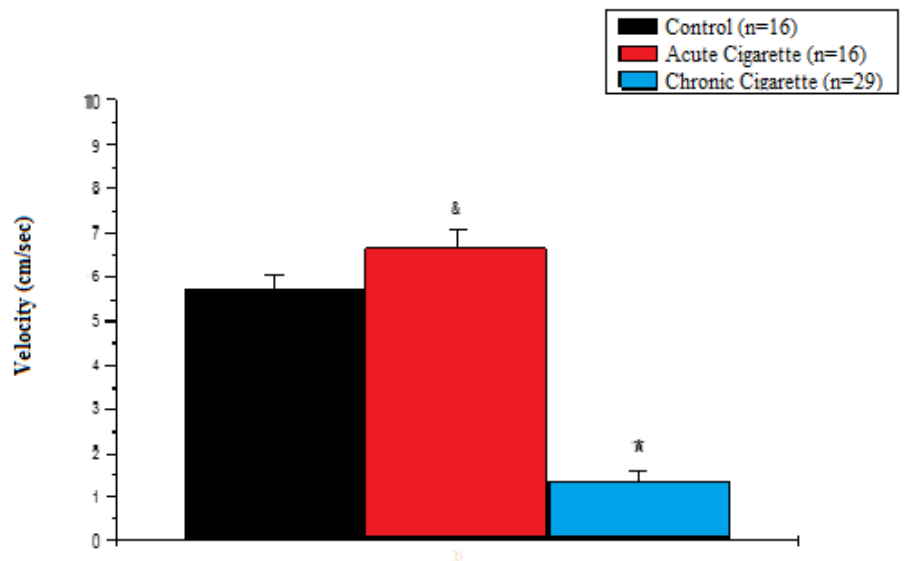

Despite the fact that no statistical difference was found in between, it has been observed that acutely affected were faster than the control group during the examination of speed parameters in the locomotor activity test. Yet, overall speed chronically affected dropped down significantly in comparison to the control group. ( $\mathrm{P}<0.001 \mathrm{Difference}$ Between Control Group and Chronically Affected). Plus, a gap between acutely and chronically affected in terms speed parametres was also spotted. (\&p<0.001 Difference Between Acutely and Chronically Affected).

Table 5. Significance Levels between the groups

\begin{tabular}{|c|c|c|c|c|}
\hline \multirow{4}{*}{$\begin{array}{l}\text { Time spent in the } \\
\text { open arms }\end{array}$} & & Acute & Chronic & Control \\
\hline & Acute & & $p<0.001$ & \\
\hline & Chronic & & & $p<0.005$ \\
\hline & Control & & & \\
\hline \multirow{4}{*}{$\begin{array}{l}\text { Total number of open } \\
\text { arm entries }\end{array}$} & & Acute & Chronic & Control \\
\hline & Acute & & $\mathrm{p}<0.001$ & \\
\hline & Chronic & & & $\mathrm{p}<0.001$ \\
\hline & Control & & & \\
\hline \multirow{4}{*}{ Distance Travelled } & & Acute & Chronic & Control \\
\hline & Acute & & $\mathrm{p}<0.001$ & \\
\hline & Chronic & & & $\mathrm{p}<0.001$ \\
\hline & Control & & & \\
\hline \multirow{4}{*}{ Velocity } & & Acute & Chronic & Control \\
\hline & Acute & & $\mathrm{p}<0.001$ & \\
\hline & Chronic & & & $\mathrm{p}<0.001$ \\
\hline & Control & & & \\
\hline
\end{tabular}

\section{Results}

The percentage of the open branch numbers of entriescompared to the total numbers of entries (both closed and open branch entries), it was seen that mice acutely exposed to cigarette smoke had a higher percentage of entry compared to the control group, however the results were notstatistically significant. The number of open branch entries observed by mice exposed chronically to cigarette smoke decreased significantly when compared to the control group ( $\mathrm{p}<0.01$ ). Furthermore, it was also observed that there was a difference in the open branch entry number between acutely and chronically affected groups. (p<0.001 Difference Between Acutely and Chronically Affected).

The total distance traveled and the speed of the mice were evaluated for 5 minutesusing Etho-Vision Video Tracking Software, when the mice were put in the center of the locomotor activity device. 
After evaluating the total distance covered during the Locomotor Activity Test, it was found that the acutely affected group covered a longer distance compared to the control group, however this was not statistically significant. Chronic exposure to cigarette smoke significantly decreased the distance covered when compared to the control group $(\mathrm{p}<0.001)$. Additionally, there was a significant difference between the chronic and the acute group. ( $p<0.001$ Difference between chronic and acute smoke exposed group)

Despite the fact that no statistical difference was found between the two, it has been observed that acutely affected were faster than the control group during the examination of speed measurements in the locomotor activity test. Yet, the overall speed of chronically affected mice decreased significantly compared with that of the control group. ( $\mathrm{P}<0.001$ Difference Between Control Group and Chronically Affected). Also, a gap between the speed of acutely and chronically affected groups was observed. ( $<<0.001$ Difference Between Acutely and Chronically Affected).

\section{Discussion and Conclusion}

In research performed by chen et al., 2005, body mass of the experimental mice and their aliment consumption decreased over the course of an 8 weeks of smoke exposure study. Our results suggets that acute exposure to cigarette smoke causes no significant change in locomotor activity, which will decrease with chronic exposure to cigarette smoke. Anxiety levels decreased with acute exposure to cigarette smoke but was not significant. However, the anxiety levels increased significantly in chronic cigarette smoke exposure.

Valenti et al., 2014 reports that acute cigarette smoke exposure reduces the amount of locomotor activity, yet we observed the opposite in our study. Anxiety results in their study were in agreement with our results that acute exposure causes no significant alteration of anxiety levels.

Caldarone et al., 2008 reported that chronic exposure to cigarette smoke led to an increase in locomotor activity, at concentrations of smoke different to that used in our study. This suggests that the amount of smoke is also important.

When the duration of stay of the mousce in the open branches of the maze (+) was examined, it was found that the exposure of acute cigarette smoke increased the duration of stay when compared to the control group, however this was statistically insignificant. Chronic cigarette exposure, however, decreased the duration of stay in the open branches significantly when compared to the control group $(\mathrm{p}<0.05)$. It was also observed that there was a difference between the acute and chronic group which could be qualified as statistically significant $(\mathrm{p}<0.001)$.

The number of open branch entries compared to the total number of branch entries insignificantly increased in the acute group compared to that of the control group. The chronic exposure group showed a significant decrease in the number of open branch entries $(p<0.01)$. The number of entries to open branch was significantly different in the acute and the chronic exposure groups $(\mathrm{p}<0.001)$.

The results of the total distance covered in the locomotor activity test found that the acutely affected group covered a greater distance in comparison to the control group, although this was not statistically significant. Mice chronically exposed to cigarette smoke significantly decreased the distance they covered compared to the control group $(\mathrm{p}<0.001)$. There was also a disparity found between the acutely and chronically affected. ( $p<0.001$ Difference Between Acutely and Chronically Affected).

When the speeds in the locomotor activity test were analyzed, it was found that the group of acutely-affected mice was faster compared to the control group, although the difference was not statistically significant. Mice chronically exposured had a significant decrease in their speed when compared with the control group $(\mathrm{p}<0.001)$. In addition to that, speed measurements of acutely and chronically affected were also found to be different. $(p<0.001$ Difference Between Acutely and Chronically Affected).

The results of this study suggest that acute cigarette smoke exposure does not significantly effect locomotor activity and anxiety in mice. However, chronic cigarette smoke exposure has significant and harmful effects. Considering the potential effects on athletic performance, exposure to cigarette smoke should be avoided by every athlete, from amateurs to elite professionals. Pharmacological and non-pharmacological approaches should be explored to reduce the cigarette consumption in athletes.

\section{References}

Aronson, K. R., Ameida, D. M., Stawski, R. S., Klein, L. C., \& Kozlowski, L. T. (2008). Smoking is Associated with Worse Mood on Stressfull Days: Result from a National Diary Study. The Society of Behavioral Medicine, 36: 259-269. https://doi.org/10.1007/s12160-008-9068-1

Caldarone, B. J., King, S. L., \& Picciotto, M. R. (2008). Sex Differences in Anxiety-Like Behavior and Locomotor Activity Following Chronic Nicotine Exposure in Mice. Neuroscience Letters, 439(2), 187-191. https://doi.org/10.1016/j.neulet.2008.05.023 
Chen, H., Vlahos, R., Bozinovski, S., Jones, J., Anderson, G. P., \& Morris, M. J. (2005). Effect of Short-Term Cigarette Smoke Exposure on Body Weight, Appetite and Brain Neuropeptide Y in Mice. Neuropsychopharmacology, 30, 713-719. https://doi.org/10.1038/sj.npp.1300597

Demirci, D., Mutlu, O., Akar, F., Celikyurt Komsuoglu, I., \& Ulak, G. (2014). Sildenafil enhances locomotor activity in young mice and exerts anxiogenic effects in both young and aged mice. Medical science monitor basic research, 20, 15-21. https://doi.org/10.12659/MSMBR.890280

Kaleli, S. (2010). Sigaranın Sağlık Üzerine Zararlı Etkileri. Fırat Sağlık Hizmetleri Dergisi, 5(14), 39-56.

Moylan, S., Jacka, F. N., Pasco, A. J., \& Berk, M. (2013). How Cigarette Smoking May Increase The Risk of Anxiety Symptoms and Anxiety Disorders: A Critical Review of Biological Pathway. Brain and Behavior, 3(3), 302-326. https://doi.org/10.1002/brb3.137

Otsuka, R., Watanabe, H., Hirata, K., Tokai, K., Muro, T., Yoshiyama, M., Takeuchi, K., \& Yoshikawa, J. (2001). Acute Effects of Passive Smoking on the Coronary Circulation in Healthy Young Adults. Journal American Medical Association, 286(4), 436-441. https://doi.org/10.1001/jama.286.4.436

Soyuer, F., Ünalan, D., \& Elmalı, F. (2011). Sigara İçmek Üniversite Öğrencilerinin Fiziksel Aktivitesini Etkiliyor Mu? Kafkas Tip Bilimleri Dergisi, 1(3), 103-108.

Taylor, A. E., Johnson, D. C., \& Kazemi, H. (1992). Environmental Tobacco Smoke and Cardiovascular Disease. American Heart Association Scientific Council, 86(2), 699-702.

Valenti, V. E., Taniguchi, R. Y., Lazarini, C. A., De Abreu, L. C., \& Goulart, F. C. (2014). Short Term Exposure to Cigarette Smoke on General Activity and Anxiety. MedicalExpress, 1(4), 180-183. https://doi.org/10.5935/MedicalExpress.2014.04.04

\section{Copyrights}

Copyright for this article is retained by the author(s), with first publication rights granted to the journal.

This is an open-access article distributed under the terms and conditions of the Creative Commons Attribution license which permits unrestricted use, distribution, and reproduction in any medium, provided the original work is properly cited. 